\title{
DESARROLLO ECONÓMICO EN CENTROAMÉRICA: VIGENCIA Y REVISIÓN DE LOS ACUERDOS DE ESQUIPULAS
}

\author{
Autores: Pedro Caldentey del Pozo ${ }^{1}$ \\ Profesor del Departamento de Economía \\ Universidad Loyola Andalucía
}

\section{Resumen}

Los acuerdos de Esquipulas ofrecieron a Centroamérica los fundamentos de un modelo de desarrollo para estas tres últimas décadas (1986-2015). Pero su impulso está agotado y se manifiesta en la debilidad de los proyectos nacionales. Las dificultades para completar los procesos de transición que ha vivido la región demandan respuestas nuevas para responder a sus problemas estructurales (desigualdad, pobreza, inadecuada inserción) y a los desafíos que plantean el cambio climático o la violencia asociada al crimen organizado. El enfoque regional puede ser una dimensión dominante en la renovación de los ejes de desarrollo. Este artículo pretende caracterizar el enfoque regional del desarrollo centroamericano

\footnotetext{
${ }^{1}$ pcaldentey@uloyola.es
} 
y justificar las variables que lo podrían convertir en dimensión predominante de las próximas décadas.

Palabras clave: integración regional; equidad; gobernanza; desarrollo.

Economic development in Central America: renewing and validity of Esquipulas Agreements

\begin{abstract}
Esquipulas agreements offered to Central America the fundamentals of a development model for the last three decades (1986-2015). However, it seems exhausted as the weakness of national development models shows in the region. Central American countries demand new proposals to respond to the structural problems (inequality, poverty, inadequate insertion) and the new challenges posed by climate change or violence associated with organized crime. The regional approach can be a key dimension in the renewal of the axes of development. This article aims to characterize the regional approach to Central American development and justify the variables that could become a dominant dimension of the coming decades.
\end{abstract}

Key Words: regional integration; equity; governance; development.

\title{
1. INTRODUCCIÓN
}

La Universidad Loyola Andalucía y la Fundación ETEA han trabajado de manera continuada en los últimos treinta años en el desarrollo de los países centroamericanos acompañando los procesos impulsados tanto por las Universidades Centroamericanas de la Compañía de Jesús como por los gobiernos y otros actores económicos y sociales en los países de la región. También lo hicieron durante estos años, a veces de manera coordinada, otras universidades de la Compañía de Jesús en España.

El impacto de la cooperación universitaria es especialmente difícil de medir al centrarse en la formación del capital humano y en el fortalecimiento de las capacidades humanas e institucionales. Pero esa cooperación ha facilitado en el entor- 
no de nuestras universidades una visión más global y equilibrada de los problemas que condicionan las políticas de desarrollo económico. De ahí su presencia en el I foro de economía UNIJES celebrado en noviembre de 2014.

La observación continuada desde finales de los años ochenta de las políticas de desarrollo en Centroamérica nos permite presentar la necesidad de renovar el modelo de desarrollo de Esquipulas y sus principales consensos como hipótesis central de este trabajo, en el marco de un escenario político y económico que es manifestación del cambio de ciclo que vive la economía global.

Entre 1989 y 1996 se firmaron en Centroamérica los Acuerdos de Paz en el marco del proceso de Esquipulas (Caldentey 2000:339) que recoge su nombre del lugar de celebración de la primera de las VI cumbres presidenciales centroamericanas que entre 1986 y 1990 facilitaron una solución regional de los conflictos de los países de la región. Guatemala, El Salvador y Nicaragua, pero también Panamá, Costa Rica y Honduras fueron durante las décadas de los setenta y los ochenta escenarios de la guerra fría y de las dictaduras militares y los movimientos revolucionarios que marcaron esas décadas en toda América Latina.

La negociación de los conflictos propició la definición en torno a Esquipulas de los principios del desarrollo en Centroamérica. La firma de los Acuerdos de Paz prometía no sólo paz en la región sino un nuevo modelo de desarrollo. Los Acuerdos de Paz trajeron paz a la región y abrieron un proceso hacia la transición democrática en un entorno de optimismo que hacía pensar en avances significativos en el desarrollo político y económico de la región.

Pero como ha señalado Edelberto Torres-Rivas (Torres-Rivas, 2011) y recoge de manera multidimensional y coral el Handbook of Central American Governance publicado por Diego Sánchez-Ancochea y Salvador Martí (Sánchez Ancochea y Marti, 2014), los procesos revolucionarios que hicieron estallar los conflictos no trajeron cambios revolucionarios en las estructuras políticas y económicas de la región. Los tres autores mencionados sostienen que los procesos de paz en Centroamérica han servido para consolidar el modelo económico predominante y que éste ha tenido un éxito reducido para aminorar las diferencias sociales y económicas en la región. Tal y como apuntan Sánchez-Ancochea y Martí (2014: 5), el desarrollo de estas tres décadas recientes no ha interrumpido un sistema económico y social basado en el dominio de sus reducidas élites y en la incapacidad del estado para asegurar un bienestar razonable y salvaguardar el estado de derecho.

Este trabajo propone como idea central:

- Que la dinámica de desarrollo generada por los acuerdos de Esquipulas se ha agotado y que eso tiene manifestaciones en varias dimensiones del desarrollo centroamericano. 


\section{Pedro Caldentey del Pozo}

- Que ese agotamiento coincide con un entorno global de cambio de ciclo caracterizado por una crisis global y por la revisión pendular de los paradigmas de desarrollo entre los enfoques de origen liberal y estructuralista que han marcado el debate económico en América latina.

- Que la región precisa de un relato renovado que inspire algunos consensos políticos y algunas políticas públicas de desarrollo y que la integración regional es un proyecto sobre el que construirlo.

Como explicaremos con más detalle en apartados posteriores, la región reúne a países que podrían ser agrupados en subconjuntos más reducidos, La máxima agregación, que podríamos denominar la región SICA, es la de los ocho países que forma el Sistema de la Integración Centroamericana y que aparecen en la tabla 1 sobre el índice de desarrollo humano de los países centroamericanos.

De entre ellos, destacan lo que a veces se denomina en la región el CA4 (Guatemala, Honduras, El Salvador y Nicaragua), los cuatro países que han participado desde el principio y plenamente en las iniciativas de integración regional y que además comparten similares condiciones de desarrollo, están en el rango de los países de desarrollo humano medio, con datos inferiores a la media latinoamericana y forman con algunos países del Caribe el conjunto de países menos desarrollado del subcontinente. Es común la referencia al Triángulo Norte (Guatemala, Honduras y El Salvador) caracterizados ahora por un particularmente elevado efecto de la violencia y la incidencia del crimen organizado y antes por no haber adoptado regímenes revolucionarios tras los conflictos de los años ochenta.

Costa Rica y Panamá, los países con mayor desarrollo humano de la región, forman un grupo particular caracterizado por unas condiciones algo mejores y por un interés más selectivo en la integración, incluso en la época actual.

Y finalmente, Belice y República Dominicana, países de desarrollo humano medio pero inferior a los anteriores, que son estados miembros del SICA aunque no participan en la dimensión económica del proceso. Se han asociado recientemente a la integración centroamericana dada su naturaleza y situación excepcional. Belice, de población todavía mayoritariamente negra y de lengua y tradición inglesa, simultáneamente miembro del CARICOM, porque es el único país continental del Caribe. Y República Dominicana porque es el único país del Caribe de tradición y lengua española, si no contemplamos el excepcional caso de Cuba. 


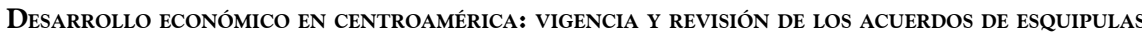

Tabla 1. Índice de Desarrollo Humano (IDH) de los países centroamericanos

\begin{tabular}{|c|c|c|c|c|c|c|}
\hline $\begin{array}{c}\text { Ranking } \\
\text { IDH }\end{array}$ & Países & IDH 2013 & $\begin{array}{l}\text { Esperanza } \\
\text { de vida } \\
\text { (años) } 2012\end{array}$ & $\begin{array}{l}\text { Media de } \\
\text { años de } \\
\text { escolaridad } \\
2012 \\
\end{array}$ & $\begin{array}{l}\text { Años de } \\
\text { escolaridad } \\
\text { previstos } \\
2012 \\
\end{array}$ & $\begin{array}{c}\text { PNB pc } \\
\text { (2011 PPP } \\
\text { US\$ }\end{array}$ \\
\hline \multicolumn{7}{|c|}{ Desarrollo Humano Alto } \\
\hline 65 & Panamá & 0,765 & 77,6 & 9,4 & 12,4 & 16.379 \\
\hline 68 & Costa Rica & 0,763 & 79,9 & 8,4 & 13,5 & 13.012 \\
\hline 84 & Belice & 0,732 & 73,9 & 9,3 & 13,7 & 9.364 \\
\hline 102 & $\begin{array}{l}\text { República } \\
\text { Dominicana }\end{array}$ & 0,700 & 73,4 & 7,5 & 12,3 & 10.844 \\
\hline \multicolumn{7}{|c|}{ Desarrollo Humano Medio } \\
\hline 115 & El Salvador & 0,662 & 72,6 & 6,5 & 12,1 & 7.240 \\
\hline 125 & Guatemala & 0,628 & 72,1 & 5,6 & 10,7 & 6.866 \\
\hline 129 & Honduras & 0,617 & 73,8 & 5,5 & 11,6 & 4.138 \\
\hline \multirow[t]{11}{*}{132} & Nicaragua & 0,614 & 74,8 & 5,8 & 10,5 & 4.266 \\
\hline & Regiones & & & & & \\
\hline & Estados Árabes & 0,682 & 70,2 & 6,3 & 11,8 & 15.817 \\
\hline & $\begin{array}{l}\text { Así del Este } \\
\text { y Pacífico }\end{array}$ & 0,703 & 74,0 & 7,4 & 12,5 & 10.499 \\
\hline & $\begin{array}{l}\text { Europa y Asia } \\
\text { Central }\end{array}$ & 0,738 & 71,3 & 9,6 & 13,6 & 12.415 \\
\hline & $\begin{array}{l}\text { América Latina } \\
\text { y el Caribe }\end{array}$ & 0,740 & 74,9 & 7,9 & 13,7 & 13.767 \\
\hline & Asia del Sur & 0,588 & 67,2 & 4,7 & 11,2 & 5.195 \\
\hline & $\begin{array}{l}\text { África } \\
\text { Subsahariana }\end{array}$ & 0,502 & 56,8 & 4,8 & 9,7 & 3.152 \\
\hline & $\begin{array}{l}\text { Países menos } \\
\text { desarrollados }\end{array}$ & 0,487 & 61,5 & 3,9 & 9,4 & 2.126 \\
\hline & $\begin{array}{l}\text { Países-Estado } \\
\text { insulares en vías } \\
\text { de desarrollo }\end{array}$ & 0,665 & 70,0 & 7,5 & 11,0 & 9.471 \\
\hline & Mundo & 0,702 & 70,8 & 7,7 & 12,2 & 13.723 \\
\hline
\end{tabular}

Fuente: UNDP (2014), pp. 177-179.

\section{EL CAMBIO DE CICLO COMO ENTORNO GLOBAL}

La crisis de la economía mundial es grave, profunda y comparable en su intensidad a las dos grandes crisis económicas del siglo XX: la de los años treinta, 


\section{Pedro Caldentey del Pozo}

desencadenada por el crash bursátil de 1929, y la de los años setenta provocada por la subida de los precios del petróleo en 1973 y 1979.

La economía mundial experimentó en los años previos a esta crisis un prolongado período de bonanza basado en la combinación excepcional de factores como el impulso provocado por la emergencia de nuevos actores económicos (en especial de China y los demás integrantes del BRIC); la expansión del comercio internacional, con precios elevados de algunos productos básicos y cierta moderación en la subida de los precios del petróleo; la abundancia de financiación externa y las facilidades tanto de acceso al crédito como de atracción de la inversión extranjera; o la posibilidad de aprovechar los beneficios de la migración tanto en los países emisores como receptores.

La crisis está teniendo también manifestaciones políticas. La respuesta ante la crisis de las formaciones G-8 y G-20, así como de las instituciones multilaterales, cuestiona la eficacia de los mecanismos e instituciones de la gobernanza global. El recurso a decisiones unilaterales o a los acuerdos entre potencias pone de manifiesto la necesidad de reconstruir la gobernanza global para atender con eficacia el funcionamiento de los procesos y actores que se mueven en el entorno de la globalización con libertad absoluta pero también con la capacidad de generar riesgos globales.

Pero por otra parte, más allá de la intensidad de los procesos más críticos, existen indicios de que esta crisis representa un punto de inflexión en el desarrollo global y el final de un período: el que ha estado marcado en las tres últimas décadas por el paradigma neoliberal y su evolución a lo largo de estos años. Repitiendo una formulación recurrente, éste no es un momento de crisis temporal o episódica, sino una crisis que esconde un cambio de época en la que se forjan nuevos paradigmas.

Pensando en que describimos este entorno como el marco en el que se manifiesta el cambio de época en Centroamérica, es importante recoger en torno al cambio de paradigmas el trabajo de revisión de las teorías del desarrollo que impulsa la Comisión para América latina y el Caribe de Naciones Unidas (CEPAL). Los debates sobre la naturaleza de la crisis de estos años han animado a la CEPAL a explorar la renovación del pensamiento keynesiano y de las nuevas teorías del comercio internacional o del nuevo institucionalismo. Uno de los trabajos que mejor recoge esta reflexión es el libro Neoestructutralismo y corrientes heterodoxas en América Latina y el Caribe a inicios del Siglo XXI (Bárcena y Prado, 2015).

La CEPAL es una fuente principal de pensamiento económico para América Latina. Sus aportaciones desde su creación en 1948 han estado siempre en el centro del debate económico de la región. Su enfoque es tradicionalmente de raíz estructuralista. La influencia del pensamiento keynesiano y de las escuelas historicistas e institucionalistas centroeuropeas fue decisiva en sus fundamentos y dio pie a la propuesta sobre el modelo de sustitución de importaciones que condicio- 
nó las políticas de desarrollo económico durante esas décadas. Tras varios años de aplicación con significativos resultados positivos en términos de industrialización y promoción de mercados integrados, el balance final del modelo quedó oscurecido por las distorsiones que generó. Éstas fueron particularmente visibles tanto en la obsolescencia industrial como en la promesa incumplida de propiciar sectores competitivos en la economía mundial, ambas provocadas particularmente por la ineficiencia y consolidación de medidas de protección y de planificación estatal que tenían una naturaleza temporal en la definición del modelo.

Desde finales de los años ochenta, las propuestas de transformación productiva y regionalismo abierto de la CEPAL apostaron también por la desregulación y la liberalización de la actividad económica. Acompañaron la orientación hacia los mercados exteriores aunque manteniendo su tradicional énfasis sobre la necesidad de promover una estructura productiva que transformase la inserción internacional de las economías latinoamericanas. Intentaron también reconducir los procesos de integración de los años sesenta en el marco del nuevo regionalismo.

En el capítulo introductorio del mencionado libro, Pérez Caldentey (2015: 81) señala como "los acontecimientos de las últimas tres décadas marcan una ruptura en la práctica de la ciencia normal en economía (el llamado paradigma dominante). La validez y justificación de este enfoque se centró, sobre todo, en la capacidad predictiva que estos acontecimientos han puesto en duda. En este sentido, se trata de un momento propicio para explorar nuevas alternativas, tanto desde la perspectiva de un mayor equilibrio entre enfoques tradicionales y novedosos de pensamiento, como sobre sus formas de enseñanza".

La obra se suma, por tanto, a la hipótesis del agotamiento del paradigma predominante y propone a partir de la tradición estructuralista de América Latina una revisión de las propuestas que ha realizado la CEPAL en la última década recuperando el fundamento neoestructuralista, desde sus trabajos sobre globalización y desarrollo a los más recientes sobre igualdad y cambio estructural para la igualdad. El análisis parte de lo que considera falencias del pensamiento ortodoxo en economía y de su falso sentido de universalidad y limitada aplicabilidad al mundo real, como planteaban las tesis estructuralistas en los años cincuenta. La propuesta de la CEPAL hace el esfuerzo de aplicar aquellas tesis estructuralistas a un contexto diferente y cambiante para proponer así nuevos temas y pautas para su desarrollo metodológico y la formulación de políticas de desarrollo.

Esta revisión de los planteamientos dominantes es perfectamente aplicable a Centroamérica donde, como ha señalado Bull (2014, p. 123), la interpretación sesgada de las ideologías ligadas al neoliberalismo se ha convertido en una de las herramientas de las élites para sostener sus privilegios ofreciendo una visión de la sociedad basada en fundamentos inadecuados. 
Otra variable que abona a la caracterización del cambio de época como agotamiento de un modelo es la explicación que ofrece el trilema político de la economía mundial de Dani Rodrik (Rodrik, 2011) y que ilustra el agotamiento de la globalización como entorno principal de las últimas décadas. La conocida propuesta de Rodrik plantea un trilema entre 3 variables ante las que solo se puede optar por dos: la hiperglobalizacion, la supervivencia de la soberanía nacional y la política democrática. El autor sugiere que aunque la opción más deseable para estos tiempos sería la de la gobernanza global, nos vemos abocados a un escenario de control de la hiperglobalizacion partiendo de acuerdos y normas globales sujetas a la discrecionalidad de los Estados.

Este análisis tiene implicaciones muy importantes para el caso centroamericano por su relevancia en los debates sobre el regionalismo o los paradigmas revisados de la integración regional en América Latina y particularmente en Centroamérica. Precisamente el autor (Rodrik, 2011, p. 225) termina su presentación del trilema planteando su propuesta con una formulación muy aplicable al debate latinoamericano afirmando que "podemos globalizar la gobernanza democrática paralelamente a los mercados; o podemos reconsiderar los acuerdos comerciales y de inversiones para ampliar el espacio para la toma de decisiones democráticas a escala nacional".

Existen, por tanto, varios elementos y categorías que permiten calificar este período como un cambio de época en el que se van a producir intensas y profundas transformaciones ligadas a nuevas tecnologías, a sistemas productivos diferentes o a intensos cambios sociales y políticos y a nuevas instituciones.

El cambio de época tiene múltiples manifestaciones que son visibles en torno a asuntos relacionados con el entorno que analiza este documento como la gobernanza global, los sistemas de representación política, la gestión de los recursos naturales, las tendencias demográficas y las tensiones migratorias, el comportamiento de los mercados mundiales en el marco de la globalización, el combate contra la exclusión o la tensión entre el regionalismo y las propuestas multilaterales.

En Centroamérica, el entorno en el que se definió el modelo de desarrollo derivado de los acuerdos de Esquipulas cambia drásticamente y la región se encuentra ante la necesidad de renovar su propuesta común de desarrollo en un mundo en plena transformación.

\section{CENTROAMÉRICA: EL MODELO DE DESARROLLOSUBYACENTE A ESQUIPULAS II}

Esquipulas ha sido el marco en el que los países centroamericanos definieron su propuesta común de desarrollo para estas tres últimas décadas pero también fue la inspiración y el marco de sus estrategias nacionales (Sánchez Ancochea y 
Martí, 2014). Centroamérica afrontó en los Acuerdos de Paz un escenario en el que se sumaban la violencia estructural asociada a los conflictos nacionales, a su regionalización y al efecto amplificador en ellos de las injerencias externas, con los efectos de la exclusión provocada por el modelo socioeconómico agroexportador al servicio de las élites.

¿Qué ofrecía el modelo de desarrollo subyacente a los Acuerdos de Esquipulas?

En materia de paz, primero de los ejes del proceso de Esquipulas, éste ofreció una metodología exitosa para la construcción de la paz a través del procedimiento para una paz firme y duradera que permitió resolver la regionalización de los conflictos, eliminar la presión externa y liberar a la región del entono de la guerra fría y canalizar los acuerdos nacionales en Nicaragua, El Salvador y Guatemala.

En materia de democracia, Esquipulas planteó el proceso de democratización como el establecimiento o perfeccionamiento de "sistemas democráticos, representativos y pluralistas que garanticen la organización de partidos políticos y la efectiva participación popular en la toma de decisiones".

Las expectativas generadas por la Declaración de Esquipulas II de 1987, que comprometía a sus mandatarios y gobiernos con el vínculo entre paz, democracia, crecimiento económico y cohesión social, sólo se han cumplido parcialmente. No obstante, es importante evitar un balance meramente negativo de estos años porque Esquipulas ofrece legados valiosos y tiene además un fuerte valor icónico para Centroamérica. Esquipulas y sus representaciones son un símbolo para una región que para liberarse de sus inercias negativas precisa de un relato que no se centre exclusivamente en conflictos y tragedias y que huya, en la medida de lo posible, de dos sesgos muy presentes en los análisis centroamericanistas y que siendo simultáneos podrían parecer contradictorios: una cierta tendencia a considerar que las circunstancias de Centroamérica son siempre excepcionales y exigen categorías particulares de análisis y otra tendencia común a aplicar a la región recetas y propuestas de desarrollo exógenas

La propuesta de este artículo no es descartar las aportaciones de los acuerdos de Esquipulas como modelo de desarrollo sino señalar cuáles han sido sus alcances en función del entorno en que se han desarrollado y según el comportamiento desplegado por los actores llamados a ser sus protagonistas. Pretendemos concluir en la necesidad de renovar los acuerdos en función del nuevo escenario global y centroamericano.

\subsection{El triple eje del modelo de Esquipulas: paz, democracia y desarrollo}

Tras los Acuerdos de Esquipulas las sociedades centroamericanas cerraron en la década de los noventa un período convulso de su historia tras años marcados por violentos conflictos internos e intrarregionales que afectaron a todos los países y en los que la región se convirtió en un campo de batalla de la guerra fría. Los 
Acuerdos de Paz de Esquipulas I y II trajeron paz a la región y abrieron un proceso de transición democrática en Centroamérica en un entorno de optimismo que hacía pensar en avances significativos en el desarrollo político y económico de la región.

Pero como citábamos anteriormente, Edelberto Torres-Rivas y otros autores (Torres-Rivas, 2011; Close, Martí y McConell, 2011) señalan que los procesos revolucionarios que hicieron estallar los conflictos no trajeron cambios revolucionarios en las estructuras políticas y económicas de la región y todavía se están cerrando algunas de las heridas abiertas de la guerra como muestran hechos recientes con valor simbólico como la beatificación de Monseñor Romero, el proceso a Ríos Montt o la revisión de algunos episodios ligados a asesinatos y matanzas.

Si el escenario de una región democratizada se ha cumplido sólo parcialmente, algo similar ha ocurrido con la democratización. La democracia se ha instalado en la región pero con debilidades institucionales significativas. Una debilidad que no sorprende porque se encuentra en los cimientos de los Estados-nación fundados en la región a finales del siglo XIX.

En materia de desarrollo económico, Centroamérica ha logrado ciertos avances al impulsar economías más diversificadas, más abiertas al exterior y con un dinámico comercio intrarregional que es la base de un mercado centroamericano con empresas de todo tamaño actuando con criterio regional. Pero los países centroamericanos no han logrado crear un cierto modelo de economía de bienestar que permita propiciar el desarrollo para alcanzar sociedades más justas, equitativas y con niveles reducidos de pobreza. Las élites centroamericanas no han sido capaces en ninguno de sus países de promover ni permitir una visión del desarrollo y de la democracia como procesos incluyentes, pluralistas y dirigidos a buscar el bienestar de la mayoría. No han sido capaces tampoco de propiciar el desarrollo de clases medias que sustentaran las dinámicas propias del desarrollo económico y social.

La construcción de la democracia y el desarrollo a partir de los acuerdos de paz tuvo también como elemento principal la reactivación del proceso de integración regional. En el marco de la nueva ola en la integración latinoamericana de los noventa, los países centroamericanos reestructuraron el MCCA transformando los viejos tratados mediante protocolos nuevos en el Sistema de la Integración Centroamericana (SICA), un esquema multidimensional que definió un nuevo marco político y estratégico y amplió el entramado jurídico e institucional.

Junto a un persistente comercio intrarregional, la integración económica ha tenido como principales actores a las empresas transnacionales y a grupos regionales de poder económico (Segovia, 2005). Si bien se generó un aumento de las exportaciones y un incremento en la inversión extranjera directa (IED), lo cierto 
es que ni la apertura comercial externa ni la integración económica han sido determinantes para frenar la concentración de la riqueza en la región y tampoco han sido exitosas en la promoción de un crecimiento sostenible de las economías que produjera oportunidades y redujera los niveles de la pobreza.

No obstante, la integración centroamericana en su dimensión económica, ha demostrado ser un escenario relevante de desarrollo y oportunidades especialmente para los tres socios con economías más desarrolladas de los países miembros de la Unión Aduanera. El mercado intracentroamericano es destinatario del $26 \%$ de las exportaciones de la región (exceptuando la maquila), con un volumen de más de 7.500 millones de dólares, frente a los 29 mil millones que alcanzaron las exportaciones totales centroamericanas en el año 2013 (SIECA, 2014, p. 9). Cifras que permiten pensar, como veremos, en el mercado regional como un marco estratégico para el desarrollo.

\subsection{Un balance preliminar de 30 años de Esquipulas}

El balance de Esquipulas es, por tanto, positivo. Tras treinta años de Esquipulas y de los acuerdos de paz, el balance de sus resultados transmite el desencanto ante algunas de las expectativas frustradas sobre una democratización profunda y sobre los cambios que iban a corregir la inequidad estructural. La región se ha transformado de forma intensa, pero ha obtenido resultados insuficientes en la corrección de los elevados índices de pobreza o de la vulnerabilidad frente a los efectos devastadores de los desastres naturales. Son en especial críticas las situaciones de violencia que se manifiestan en una de las más altas tasas mundiales de homicidios dolosos, en particular en el llamado Triángulo Norte (Banco Mundial, 2011). La democracia formal está instalada en toda la región pero en un contexto de debilidad de las instituciones y sometida a los efectos de la corrupción. A ello debemos sumar las recientes crisis políticas en Guatemala, Honduras y Nicaragua, los diferendos territoriales y la debilidad de los partidos políticos en casi toda la región.

La propuesta de la triple transición que ofrecen Salvador Martí y Diego Sánchez-Ancochea, en su reciente Handbook of Central American Governance, ayuda a precisar las luces y sombras de estas décadas y es una extraordinaria base para pensar en las siguientes. Los mencionados autores (Marti y Sánchez-Ancochea, 2014, p. 4) proponen el balance de estos años a partir de los tres procesos de transición de la región: (i) de la guerra a la paz; (ii) desde el autoritarismo a la democracia, (iii) desde un modelo estadocéntrico y agroexportador a otro neoliberal basado en productos no tradicionales y en las remesas.

Salvador Martí y Diego Sánchez-Ancochea (2014, p. 5) destacan el carácter específico y único de la transición a la democracia que propició Esquipulas en Centroamérica. Se trata de una transición que se caracteriza más por ser fundación de un nuevo régimen democrático que por ser un proceso de redemocratiza- 
ción, ya que se desarrolla en un escenario de conflicto abierto, con un conjunto de actores diferente al de los episodios previos (guerrilla y gobiernos, élites económicas y agentes externos) y por la enorme relevancia del conflicto centroamericano en el panorama geopolítico de la época.

Como también señalaba Torres Rivas (2011), los autores afirman que los ejes del modelo de desarrollo subyacente que promovían su triple transición se han agotado o han llegado a su máximo alcance. Por un parte, se ha instalado en la región una democracia formal con elecciones regulares y pacíficas y con separación de poderes pero hay profundas debilidades institucionales que fuerzan a considerar a algunas democracias de la región como regímenes híbridos o semidemocracias.

Por otra, el modelo de desarrollo no ha conseguido romper con la predominancia de lo privado sobre lo público, de lo individual sobre lo colectivo. Algunos actores privados y externos (grupos empresariales, organismos internacionales, redes ilegales) tienden a imponer sus intereses sobre el interés general, interrumpiendo procesos de transformación productiva o de reforma institucional esenciales (la fiscal ha recobrado fuerza en estos años) e impidiendo que funcionen mecanismos redistributivos del crecimiento. Los trabajos de Bull (2014) sobre la convivencia de estados débiles con élites fuertes en Centroamérica refuerzan esta idea.

En definitiva, el legado de Esquipulas ha sido trascendente para Centroamérica pero se ha agotado el conjunto de consensos que permitieron definir los ejes de desarrollo de las tres últimas décadas. Ya no es funcional para un entorno muy diferente al original y en el marco de un cambio de época que supone una renovación de paradigmas y posiblemente transformaciones sustanciales en los procesos y modos de producción y transformaciones políticas y sociales de carácter global.

El agotamiento del modelo de desarrollo aplicado en la región tiene una doble vertiente: la regional y la nacional. Aunque las condiciones en las que los países lo deben hacer son diferentes, todos ellos se enfrentar a la necesidad de definir respuestas a los retos del desarrollo en un incierto cambio de época.

\section{LOS RETOS DEL DESARROLLO ECONÓMICO EN CENTROAMÉRICA PARA LAS PRÓXIMAS DÉCADAS}

Los retos a los que se enfrenta Centroamérica en los próximos años son variados y complejos. Además de trabajar en los elementos incompletos de la triple transición, hay otros nuevos frentes. La acelerada transformación de los países centroamericanos en sociedades más urbanas que rurales o el cambio en las tendencias demográficas hacia el envejecimiento de la población, son buenos ejemplos. Pero en este artículo nos vamos a centrar en revisar la dimensión económica de la estrategia de desarrollo en Centroamérica y su evolución. 


\subsection{Rasgos actuales de las economías centroamericanas}

Antes de presentar los argumentos al respecto, la tabla 2 nos ofrece una fotografía de la región con los últimos datos actualizados.

Tabla 2. Principales indicadores económicos de los países centroamericanos

\begin{tabular}{|l|c|c|c|c|c|c|c|}
\hline $\begin{array}{c}\text { Países región } \\
\text { SICA }\end{array}$ & $\begin{array}{c}\text { PIB real } \\
\text { 2013, } \\
\text { millones de } \\
\text { US\$, año } \\
\text { base 2005 }\end{array}$ & $\begin{array}{c}\text { Tasa } \\
\text { crecimiento } \\
\text { PIB real } \\
2013\end{array}$ & $\begin{array}{c}\text { PIB pc real } \\
2013\end{array}$ & $\begin{array}{c}\text { Tasa } \\
\text { crecimiento } \\
\text { PIB pc real } \\
2013\end{array}$ & $\begin{array}{c}\text { Presión } \\
\text { fiscal 2013 }\end{array}$ & $\begin{array}{c}\text { Deuda } \\
\text { pública total } \\
2013\end{array}$ & $\begin{array}{c}\text { Tasa anual } \\
\text { de inflación }\end{array}$ \\
\hline Belice & $1.355,5$ & 0,7 & $3.875,9$ & $-1,9$ & 26,1 & 79,0 & 1,8 \\
\hline Costa Rica & $28.428,7$ & 3,5 & $6.031,8$ & 2,2 & 21,0 & 54,7 & 3,7 \\
\hline El Salvador & $19.434,5$ & 1,7 & $3.089,5$ & 1,0 & 15,7 & 61,4 & 0,8 \\
\hline Guatemala & $36.234,9$ & 3,7 & $2.347,1$ & 1,2 & 12,3 & 25,5 & 4,4 \\
\hline Honduras & $12.888,2$ & 2,6 & $1.506,5$ & 0,6 & 17,5 & 54,9 & 4,9 \\
\hline Nicaragua & $8.458,6$ & 4,6 & $1.378,9$ & 3,5 & 19,5 & 49,7 & 7,1 \\
\hline Panamá & $30.787,1$ & 8,4 & $7.995,1$ & 6,6 & 18,5 & 36,8 & 4,0 \\
\hline $\begin{array}{l}\text { Rep. } \\
\text { Dominicana }\end{array}$ & 59333.3 & 4,8 & $5,768,8$ & 2,8 & 14,0 & 38,3 & 3,9 \\
\hline
\end{tabular}

Fuente: Programa Estado de la Región (2014). Estadísticas de Centroamérica 2014, indicadores económicos. Excepto los datos correspondientes a República Dominicana que se completaron a partir de CEPAL (2014). Estudio económico de América Latina y el Caribe 2014, anexo Rep. Dominicana.

Como se puede deducir de los datos de la tabla 2, los países centroamericanos se caracterizan por los siguientes rasgos:

- Tamaño económico individual y conjuntamente muy reducido;

- renta per cápita baja, con una media de poco más de tres mil dólares USA -con la excepción de Panamá, Costa Rica y Rep. Dominicana- frente a la media de seis mil en América latina y el Caribe y de más de treinta mil en la OCDE, con datos de 2013;

- tasas de crecimiento muy moderadas, con la excepción de Panamá que construye infraestructuras de gran alcance (ampliación de canal, metro urbano y otras) y de Nicaragua (probablemente por la construcción de infraestructuras y el apoyo del capital venezolano); 
- estabilidad macroeconómica no especialmente comprometida en términos de inflación o déficit fiscal;

- balanzas fiscales comprometidas, no tanto por el volumen de deuda y gasto, sino por la falta de ingresos (algunos países centroamericanos tienen de las tasas de presión fiscal más bajas del mundo) y la incapacidad de endeudamiento.

Otros indicadores económicos (ver tabla 3), relacionados con la balanza de pagos y la financiación externa de sus economías, ponen mejor de manifiesto algunas de las vulnerabilidades de los países centroamericanos.

\section{Tabla 3. Indicadores de Balanza de pagos y financiación externa en los países centroamericanos (datos de 2013, en porcentaje del PIB)}

\begin{tabular}{|l|c|c|c|c|c|c|c|c|c|}
\hline \multicolumn{1}{|c|}{ Paises } & $\begin{array}{c}\text { Balanza } \\
\text { por } \\
\text { cuenta } \\
\text { corriente }\end{array}$ & $\begin{array}{c}\text { Balanza } \\
\text { comer- } \\
\text { cial (\% } \\
\text { del PIB) }\end{array}$ & $\begin{array}{c}\text { Balan- } \\
\text { za de } \\
\text { servicios } \\
\text { (\% del } \\
\text { PIB) }\end{array}$ & $\begin{array}{c}\text { Ingresos } \\
\text { por tu- } \\
\text { rismo (\% } \\
\text { del PIB) } \\
2012\end{array}$ & $\begin{array}{c}\text { Balanza } \\
\text { de rentas }\end{array}$ & $\begin{array}{c}\text { Balanza } \\
\text { de trans- } \\
\text { ferencias }\end{array}$ & Remesas & $\begin{array}{c}\text { Balanza } \\
\text { de cuen- } \\
\text { ta de } \\
\text { capital } y \\
\text { finan- } \\
\text { ciera }\end{array}$ & $\begin{array}{c}\text { Inversión } \\
\text { extran- } \\
\text { jera } \\
\text { directa }\end{array}$ \\
\hline Belice & $-5,1$ & $-22,8$ & 18,3 & 20,3 & $-6,9$ & 6,3 & n.d. & 9,2 & 6,8 \\
\hline Costa Rica & $-5,6$ & $-12,4$ & 8,6 & 5,0 & $-2,4$ & 0,7 & 1,2 & 7,4 & 6,0 \\
\hline El Salvador & $-6,5$ & $-21,8$ & 2,4 & 3,2 & $-4,0$ & 16,9 & 16,3 & 3,9 & 0,6 \\
\hline Guatemala & $-2,9$ & $-12,2$ & $-0,1$ & 2,8 & $-2,4$ & 11,9 & 10,1 & 5,0 & 2,6 \\
\hline Honduras & $-5,6$ & $-16,8$ & $-2,6$ & 3,7 & $-5,2$ & 19,0 & 16,8 & 5,5 & 5,7 \\
\hline Nicaragua & $-11,4$ & $-20,3$ & $-0,5$ & 4,0 & $-2,8$ & 12,2 & 9,6 & 13,9 & 7,5 \\
\hline Panamá & $-11,3$ & $-15,8$ & 11,8 & 7,8 & $-7,2$ & $-0,1$ & 0,9 & 13,5 & 10,2 \\
\hline $\begin{array}{l}\text { Rep. } \\
\text { Dominicana }\end{array}$ & $-4,2$ & $-12,4$ & 6,2 & 8,4 & $-4,8$ & 7,0 & 7,2 & 6,4 & 3,4 \\
\hline
\end{tabular}

Fuente: Programa Estado de la Región (2014). Estadísticas de Centroamérica 2014, indicadores económicos. Excepto los datos correspondientes a República Dominicana que se completaron a partir de CEPAL (2014). Estudio económico de América Latina y el Caribe 2014, pp.185 y ss.

La tabla 3 muestra una serie de indicadores que nos permiten añadir los siguientes elementos al perfil macroeconómico de los países centroamericanos a partir de su sector externo:

- Todos los países centroamericanos enfrentan déficits comerciales muy importantes a partir de los patrones de comercio clásicos de países en desarro- 
llo. La falta de economías de escala en países de tamaño tan reducido agrava la intensidad de este déficit.

- La balanza por cuenta corriente es también netamente negativa pese a las cifras significativas de superávit en la balanza de servicios gracias a los ingresos turísticos y por la importancia de las remesas de emigrantes en la balanza de transferencias.

- El comportamiento de la balanza por cuenta de capital y financiera es positivo pero irregular, como muestra la disparidad de las cifras de inversión extranjera directa que no ha podido comportarse como el factor de equilibrio que las políticas de apertura y liberalización prometía.

- Las remesas son el factor de financiación externa más importante de varias de las economías centroamericanas por encima de otros factores relevantes como el turismo o la inversión extranjera.

Pero los indicadores macroeconómicos nos proporcionan una información insuficiente para completar el análisis de las economías centroamericanas. Varias de las principales debilidades y factores de vulnerabilidad de la región están asociados a indicadores sociales que constituyen el principal obstáculo para el éxito de las estrategias de desarrollo (ver tabla 4).

Tabla 4. Indicadores sociales de los países centroamericanos

\begin{tabular}{|l|r|r|r|r|r|r|r|r|r|}
\hline \multicolumn{1}{|c|}{ PAÍSES } & $\begin{array}{c}\text { Pobla- } \\
\text { ción } \\
\text { (miles) } \\
2013\end{array}$ & $\begin{array}{c}\% \text { po- } \\
\text { blación } \\
\text { urbana } \\
2011\end{array}$ & $\begin{array}{c}\text { \% } \\
\text { Pobreza } \\
2011\end{array}$ & $\begin{array}{c}\% \\
\text { pobreza } \\
\text { extrema } \\
2011\end{array}$ & $\begin{array}{c}\text { Índice } \\
\text { de Gini } \\
2011\end{array}$ & $\begin{array}{c}\text { Gasto } \\
\text { público } \\
\text { en edu- } \\
\text { cación } \\
2011\end{array}$ & $\begin{array}{c}\% \\
\text { Gasto } \\
\text { Público } \\
\text { en salud } \\
2011\end{array}$ & $\begin{array}{c}\text { Acceso } \\
\text { a agua } \\
\text { potable } \\
2012\end{array}$ & $\begin{array}{c}\text { Acceso } \\
\text { a sanea- } \\
\text { miento } \\
2012\end{array}$ \\
\hline Belice & 350 & 52,7 & n.d. & n.d. & n.d. & 7,2 & 3,8 & 99 & 91 \\
\hline Costa Rica & 4.713 & 72,8 & 24,8 & 7,3 & 0,515 & 7,0 & 7,6 & 97 & 94 \\
\hline El Salvador & 6.290 & 62,2 & 47,5 & 15,5 & 0,441 & 3,4 & 4,3 & 90 & 70 \\
\hline Guatemala & 15.438 & 49,0 & 53,7 & 13,3 & 0,524 & 2,9 & 2,4 & 94 & 80 \\
\hline Honduras & 8.555 & 52,7 & 67,6 & 43,9 & 0,552 & 6,4 & 4,1 & 90 & 80 \\
\hline Nicaragua & 6.134 & 57,3 & 44,1 & 8,2 & 0,340 & 5,0 & 4,1 & 85 & 52 \\
\hline Panamá & 3.851 & 76,0 & 25,3 & 12,4 & 0,531 & 3,8 & 5,4 & 94 & 73 \\
\hline $\begin{array}{l}\text { Rep. } \\
\text { Dominicana }\end{array}$ & 10.400 & 68,7 & 43,2 & 20,3 & 0,558 & 2,4 & 1,8 & 83 & 85 \\
\hline
\end{tabular}

Fuente: Programa Estado de la Región (2014). Estadísticas de Centroamérica 2014, indicadores económicos. Excepto los datos correspondientes a República Dominicana que se completaron 


\section{Pedro Caldentey del Pozo}

a partir de CEPALSTAT, base de datos y estadísticas de la CEPAL. El dato del Índice de Gini de Guatemala está tomado de la DATABANK del World Bank.

Los datos de la tabla 4 completan el perfil de los países centroamericanos con datos que permiten caracterizarlos como países pequeños y crecientemente urbanos marcados por la alta incidencia de la pobreza - con datos diferenciados para Costa Rica y Panamá - y de la desigualdad.

Algunos elementos definitorios de la pobreza ofrecen resultados positivos como el acceso al agua potable o las tasas de alfabetización (no recogidas en el cuadro pero muy altas para todos los países excepto para Guatemala). Sin embargo, un análisis pormenorizado de las cifras distinguiendo su comportamiento por sexos o áreas geográficas, ayudarían a poner en evidencia los fenómenos de exclusión que se dan en la región. El análisis de los volúmenes absolutos de gasto público social y de la eficacia de las políticas sociales abunda en el problema de la exclusión de determinados sectores de la población centroamericana.

\subsection{La vigencia de las estrategias de desarrollo aplicadas en Centroamérica}

La CEPAL presentó en el año 2013 (CEPAL, 2013) un balance de lo ocurrido en la economía latinoamericana en los años previos bajo el subtítulo de "tres décadas de crecimiento desigual e inestable". El balance es muy sugerente para el debate que plantea este documento. En estas tres décadas previas, bajo el dominio del paradigma neoliberal, Latinoamérica ha mantenido un comportamiento marcado por la crisis de endeudamiento de los años ochenta; por el crecimiento inestable y el ajuste estructural sometido a choques externos y desequilibrios internos de los años noventa; y por el crecimiento variable en un entorno favorable que ha caracterizado la última década que sin embargo se ve amenazado por perspectivas de crisis o de estancamiento derivadas de factores internos o externos.

Es un entorno aplicable a Centroamérica aunque asistimos a un progresivo desencaje por parte de Centroamérica de la realidad y el discurso global latinoamericano que anima a desligar en varios ámbitos el análisis centroamericano del latinoamericano. Las tendencias de crecimiento a corto plazo de México y Centroamérica y las de los países sudamericanos ilustran también la divergencia de sus economías. El desempeño de los países centroamericanos está asociado a la economía estadounidense y no a los factores de crecimiento de los países del Sur en el subcontinente latinoamericano. También la CEPAL ha hecho aportaciones relevantes sobre la naturaleza de los problemas de las pequeñas economías de Caribe y Centroamérica en América Latina. Y es particularmente útil en este debate el documento Centroamérica y República Dominicana: crecimiento, ciclos y transformación económica, 1990-2011 (CEPAL 2012b). 
¿Qué podemos decir sobre el resultado de veinte años de esfuerzos para la inserción internacional de la Región centroamericana? Tras tres décadas aplicando políticas para el desarrollo y la inserción de la economía de la subregión centroamericana en la economía mundial, existe la suficiente experiencia para reflexionar sobre sus resultados y reformular la estrategia de la subregión y afrontar estos tiempos de cambio en el paradigma global.

Es particularmente necesario repensar dos de los beneficios clásicos que se atribuyen a la liberación comercial que ha sido el eje de la propuesta de desarrollo económico de la región (Caldentey 2014: 19).

- En primer lugar, se debe plantear si los beneficios en términos de bienestar y desarrollo que se atribuyen a mayores flujos comerciales son tales. Los recientes documentos de la CEPAL que hemos mencionado y otros trabajos (Evenett y Vines 2012, Fiorentino 2011, Wonacott y Wonacott 2011) señalan que no hay datos contundentes ni pruebas concluyentes sobre los efectos netamente positivos en el desarrollo y bienestar de los países en desarrollo derivados de la liberalización multilateral o de los acuerdos de libre comercio. Del mismo modo, no se puede pasar por alto el hecho de que los incrementos de la renta no afectan por igual a la población y que un aumento de la renta media puede no significar un aumento del bienestar total. Actualmente, países de la región que ha sido destacados ejemplos por su internacionalización, como Costa Rica y Panamá, registran niveles de desigualdad relativamente mayores al de los países más pobres de la región (Estado de la Región 2014). La mayor desigualdad viene dada por los naturales desequilibrios entre la productividad del sector vinculado al comercio internacional y el sector productivo interno. Pero se consolida porque la ausencia de políticas eficaces de prestación de servicios públicos y la reducida capacidad de gasto de todos los países de la región (ICEFI 2012:61) impide que el incremento de actividad y producción asociado a las exportaciones se distribuya al conjunto de la economía. Los ingresos tributarios representaron en promedio en el año 2014 un 13,7\% del PIB. Las cifras de Costa Rica $(13,2 \%)$ y de Panamá $(10,5 \%)$ son menores a la media (ICEFI 2015:7). Incluso son menores en Panamá que en Guatemala (10,9\%), un país mencionado recurrentemente como ejemplo de baja presión fiscal y de resistencia a las reformas en ese ámbito.

- En cuanto al regionalismo abierto, la estrategia se mostró cómo un factor determinante en la apertura comercial experimentada por la economía global en las últimas décadas tanto multilateralmente como por bloques regionales. El regionalismo abierto ha promovido una mayor eficiencia y el incremento de intercambios comerciales. Sin embargo, su impacto en el bienestar global, particularmente de los países en desarrollo, no ha sido 


\section{Pedro Caldentey del Pozo}

tan evidentemente eficiente como prometía. La propuesta tuvo la virtud de permitir el desarrollo simultáneo de estrategias de inserción internacional e integración económica con objetivos que no siempre eran complementarios aunque se acogieran a procesos de apertura comercial y desregulación.

Después de treinta años de vigencia del paradigma económico ortodoxo, éste da muestras de agotamiento y se manifiesta en las dudas generadas en torno al escenario multilateral y las propuestas de liberalización. La crisis de estos últimos años remite a patrones de comportamiento antiguos que han dado pie al concepto de "neoproteccionismo". Este marco analítico es relevante actualmente porque el escenario del regionalismo está condicionado por:

a) el debate sobre los efectos y límites de la globalización;

b) la crisis del libre comercio multilateral ante las dificultades de lograr acuerdos sustanciales en el marco multilateral de la Ronda de Doha;

c) la profusión de soluciones regionalistas al atasco multilateral, esta vez especialmente entre países desarrollados, como en el caso del TTIP y el TPP;

d) la ausencia de evidencias indiscutibles que demuestren la mayor eficiencia y eficacia de los acuerdos de libre comercio sobre iniciativas de integración económica;

e) el agotamiento de las oportunidades asociado al comercio norte-sur, objeto principal de atención del regionalismo abierto, y por el crecimiento del comercio sur-sur más proclive a acuerdos regionales de integración económica con uniones aduaneras y políticas de desarrollo económico;

f) y la recuperación del interés en los procesos de desarrollo, las oportunidades asociadas al comercio y a los mercados intrarregionales y a los acuerdos regionales que los promueven.

Las características del entorno han cambiado definitivamente en esta transición a un nuevo ciclo y la propuesta de regionalismo abierto está en franca revisión. Su crisis no debe ser, sin embargo, entendida desde una posición de conflicto entre los acuerdos de libre comercio y los acuerdos de integración regional sino por la necesidad de asegurar su complementariedad y, particularmente, a otorgar relevancia a la agenda complementaria de los acuerdos y a la agenda política y económica del desarrollo.

¿Qué cabe esperar entonces? Los períodos de transición no se caracterizan por la facilidad para detectar con precisión los paradigmas que se impondrán a medio plazo. Pero en el marco de este posicionamiento centroamericano ante el cambio de época se pueden aportar dos elementos para el debate:

Por una parte, estos hechos invitan a analizar y estudiar las características estructurales internas que explican las dinámicas de desarrollo económico de los 
países centroamericanos. El simple hecho de registrar mayor apertura o mayores intercambios comerciales no implica por sí solo, mayores niveles de desarrollo socio-económico, especialmente en los países menos avanzados. Las fuentes de crecimiento no son exclusivamente externas. Hay que revisar las potencialidades de los sectores productivos centroamericanos y desafiar las hipótesis de desarrollo con las que ha trabajado la región estos años y que centraban la atención casi exclusivamente en captación de inversión extranjera, la recepción pasiva de las remesas, la promoción indiscriminada de la apertura comercial y la dependencia de una menguante cooperación internacional para el impulso de los proyectos estratégicos de nación y región.

Por otra parte, el paradigma del regionalismo abierto ha cumplido sus funciones y no parece ya funcional para América Latina ni para América Central (Caldentey 2014). Ha promovido la competitividad de algunos sectores ligados al comercio exterior y la apertura de las economías latinoamericanas. Pero su enfoque resulta insuficiente para promover la distribución de sus efectos positivos y el desarrollo de las fuentes internas de crecimiento o el cambio productivo de las economías latinoamericanas para corregir su sesgo hacia el excesivo protagonismo de la exportación de materias primas. El regionalismo latinoamericano se desarrolla en torno a paradigmas revisados y a nuevas funciones en torno a nuevas iniciativas de carácter distinto como UNASUR o la Alianza del Pacífico.

El protagonismo de la integración centroamericana es reducido en el debate latinoamericano pero su experiencia en torno a determinados enfoques y avances puede ser significativa como desarrollamos en el apartado siguiente.

\subsection{El debate sobre el regionalismo y la integración en Centroamérica}

El regionalismo latinoamericano de los últimos años se ha caracterizado por registrar una abundante oferta de propuestas integracionistas de distinta naturaleza. Amparado por la permisividad epistemológica y por la ambigüedad semántica del término "integración", han surgido proyectos regionalistas basados en la integración regional, en el libre comercio, en el asociacionismo o en la cooperación regional, con objetivos diferenciados y distintos niveles de participación. La flexibilidad ha sido tal que varios países forman ahora parte de procesos diferentes cuya complementariedad no es evidente. Las modalidades del regionalismo latinoamericano se pueden agrupar en tres grandes grupos (Caldentey 2014:22):

a) Bloques de libre comercio y espacios de preferencias arancelarias, como la Asociación Latinoamericana de Integración (ALADI), el Tratado de Libre Comercio de América del Norte (TLCAN), el DR-CAFTA, los múltiples 
acuerdos bilaterales existentes entre países latinoamericanos y terceros; o la emergente y novedosa Alianza del Pacífico.

b) Procesos de integración regional cuyo objetivo es la conformación de una unión aduanera y la profundización en políticas comunes, como la Comunidad Andina (CAN), la CARICOM, el Mercado Común del Sur (MERCOSUR) o el SICA.

c) Procesos de cooperación, colaboración y complementariedad en temas de desarrollo, políticos, sociales y económicos, como el ALBA-TCP, la Asociación de Estados del Caribe (AEC), la CELAC, la Organización del Tratado de Cooperación Amazónica (OTCA), el Proyecto Mesoamérica y la Unión de Naciones Suramericanas (UNASUR).

Este entorno de transformación de paradigmas y la limitación de los alcances de la estrategia de inserción derivada de Esquipulas y del regionalismo abierto, explica la tibieza con la que los países centroamericanos observan los impactos actuales y venideros del DR-CAFTA, del Acuerdo de Asociación entre la UE y Centroamérica (AAUECA) y de otros acuerdos como los firmados con China.

La integración centroamericana nació en 1951 pero su relevancia como uno de los procesos pioneros latinoamericanos de integración nace de la puesta en marcha del llamado Mercado Común Centroamericano (MCCA) en 1960 con la firma del Tratado General de integración económica. Basado en la industrialización sustitutiva de importaciones, el MCCA se desarrolló de forma muy positiva durante los años sesenta y setenta. Pero los conflictos políticos de la región interrumpieron su desarrollo de forma dramática en los años ochenta, con el poderoso incentivo del consenso sobre el agotamiento de la estrategia de industrialización.

No obstante, aunque bajo mínimos, los países centroamericanos mantuvieron los fundamentos de la integración económica lo que permitió recuperar el proyecto de la unión aduanera con la renovación del SICA en los primeros años noventa. En los acuerdos de Paz, la integración jugaba un rol destacado como instrumento de las estrategias de desarrollo, pero la unión aduanera no es ya concebida como eje central de la integración sino como un objetivo de una de sus dimensiones.

En la actualidad, se puede afirmar que Centroamérica dispone de una unión aduanera imperfecta basada en las siguientes condiciones:

- Formada por Guatemala, El Salvador, Honduras, Nicaragua, Costa Rica y Panamá que se ha incorporado recientemente y está adoptando progresivamente el acervo legal asociado a la unión aduanera (no participan ni Republica Dominicana ni Belice) 
- Libre comercio intrarregional con la única excepción del café sin tostar y el azúcar de caña entre los seis socios y restricciones bilaterales en torno a café tostado, alcohol etílico, derivados del petróleo y bebidas alcohólicas destiladas.

- Un amplio desarrollo normativo común sobre medidas de salvaguardia, origen de las mercancías, prácticas desleales, tránsito aduanero, medidas sanitarias y fitosanitarias, barreras no arancelarias, controversias comerciales, administración aduanera, transporte regional y otros asuntos.

- Un arancel externo común que cubre todo el universo arancelario menos el 4,3\% de los rubros que permanece desarmonizado por la sensibilidad de los intereses en trono a ellos (sobre todo productos agrícolas pero también productos industriales como metales, maderas y medicamentos).

El principal problema de la unión aduanera está relacionada, sin embargo, con las incongruencias de los países miembros en su política comercial externa. El arancel externo se enfrenta a negociaciones por separado que conceden preferencias arancelarias no comunitarias y que minoran en la práctica la eficacia de la Unión aduanera y su legitimidad ante los productores y empresarios.

La región tiene acuerdos conjuntos (con listas de desgravación individuales) con Estados Unidos y República Dominica y con la Unión Europea (AAUECA). Está negociando con México la consolidación en un solo acuerdo de los tres que están vigentes por separado y que se aplican bilateralmente. Tiene un TLC (acuerdo o tratado de libre comercio con República Dominicana de aplicación bilateral. Los países firmaron TLC, de negociación y aplicación bilateral, con Chile. Además Costa Rica y Honduras tienen TLC bilateral con Canadá (los demás están negociándolo). Costa Rica ha firmado TLC bilateral con la Rep. Popular de China, Singapur y CARICOM. Todos han firmado TLC de aplicación bilateral con Perú menos Nicaragua. El Salvador, Honduras y Guatemala lo firmaron con Colombia. Y Nicaragua, Guatemala y El Salvador negociaron y aplican bilateralmente su TLC con Taiwán. Todo ello configura una compleja y centroamericana versión del famoso Spaguetthi Bowl de Jagdhis Bhagwati.

Los incentivos que estos acuerdos ofrecen, su presumible impacto a corto plazo, la presión del mainstream económico para la promoción de este tipo de acuerdos y la falta de instrumentos jurídicos del Sistema para prevenir estos comportamientos poco compatibles con los acuerdos regionales son algunas de las causas que explican esta práctica.

Por otra parte, el porcentaje de comercio intrarregional en la Unión Aduanera Centroamericana es el más alto del regionalismo latinoamericano. Los países del todavía a veces llamado MCCA (SIECA 2014:10), constituyen el segundo 


\section{Pedro Caldentey del Pozo}

mercado para la región (26\% de las exportaciones y $12,9 \%$ de las importaciones). El primer socio es Estados Unidos (32,5\% de las exportaciones y 40,5 de las importaciones). La UE es el tercer destino de las exportaciones $(13,1 \%)$ y sólo el quinto mercado de origen de las importaciones (12,9\%). China y México (7,6\% y $7,9 \%$ respectivamente) son también dos países importantes en las importaciones centroamericanas.

Este conjunto irregular de acuerdos es el marco comercial del que se han dotado los países centroamericanos. No existen todavía estudios que permitan definir hipótesis alternativas sobre el efecto potencial de acuerdos gestionados de otra manera. La competitividad en mercados y sectores de los países centroamericanos no ha sido especialmente positiva durante los años de la crisis excepto en el comercio intrarregional que pareció jugar un cierto rol compensador de la caída de mercados en terceros países. En estos años de crisis, mientras Sudamérica discute la crisis del mercado regional y de los intercambios Sur-Sur, los países centroamericanos parecen ganar competitividad en sus principales mercados y en varios de sus principales productos de exportación (Cordero 2014: 53-54). La evolución reciente de las economías latinoamericanas parece confirmar que los países centroamericanos y caribeños, como México, no comparten los ciclos económicos de los países sudamericanos. La explicación es su estrecha relación con el comportamiento de la economía estadounidense.

Una limitante evidente para el desarrollo de la región - y para prever el impacto de sus estrategias de desarrollo - es el tamaño de sus economías. La tabla 5 presenta, ordenados los países de menor a mayor volumen, el PIB de los países latinoamericanos y del Caribe. El peso relativo de cada uno de los 8 países centroamericanos es muy reducido y sólo superan a los países caribeños, aunque no a todos. La suma del tamaño específico de sus economías con la condición de países de desarrollo limitado y las vulnerabilidades particulares de la región, ofrecen argumento difícilmente irrefutables para la acción conjunta. La suma de las economías centroamericanas sitúa el conjunto a la altura de la economía venezolana o chilena. Se trata de una suma de tamaños difícil de ejecutar y gestionar de forma eficiente pero debería servir como incentivo para definir estrategias. Algunos de los principales grupos de interés y liderazgo nacional se manifiestan con frecuencia recelosos ante la ruptura del status quo que la acción conjunta, la cooperación o la integración pueden provocar. Y ese es un problema tradicionalmente decisivo para su implementación. 


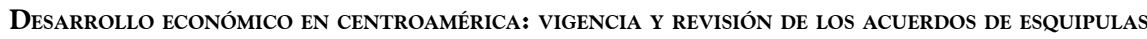

Tabla 5. Ranking de tamaño económico de los países latinoamericanos.

PIB total anual, en millones de dólares, a precios constantes en dólares de 2010 . Ordenado de menor a mayor volumen

\begin{tabular}{|c|c|c|c|c|}
\hline País & 1990 & 2000 & 2014 & \begin{tabular}{|c|} 
Porcentaje \\
sobre PIB total \\
LAC 2014 \\
\end{tabular} \\
\hline Dominica & 258,97 & 376,42 & 492,85 & $0,01 \%$ \\
\hline San Vicente y las Granadinas & 376,90 & 512,49 & 700,44 & $0,01 \%$ \\
\hline Saint Kitts y Nevis & 313,82 & 561,45 & 767,44 & $0,01 \%$ \\
\hline Granada & 429,82 & 646,27 & 816,67 & $0,01 \%$ \\
\hline Antigua y Barbuda & 695,59 & 949,40 & $1.196,51$ & $0,02 \%$ \\
\hline Santa Lucía & 780,46 & $1.044,79$ & $1.214,58$ & $0,02 \%$ \\
\hline Belice & 529,58 & 949,42 & $1.554,79$ & $0,03 \%$ \\
\hline Guyana & $1.106,72$ & $1.795,42$ & $2.730,65$ & $0,05 \%$ \\
\hline Barbados & $3.560,65$ & $3.954,75$ & $4.497,49$ & $0,08 \%$ \\
\hline Suriname & $2.571,27$ & $2.646,97$ & $5.039,15$ & $0,09 \%$ \\
\hline Haití & $6.643,50$ & $6.641,08$ & $7.804,44$ & $0,14 \%$ \\
\hline Bahamas & $5.795,58$ & $7.372,03$ & $8.219,52$ & $0,14 \%$ \\
\hline Nicaragua & $4.738,31$ & $6.612,89$ & $10.682,72$ & $0,19 \%$ \\
\hline Jamaica & $10.068,46$ & $10.838,85$ & $13.512,06$ & $0,24 \%$ \\
\hline Honduras & $7.649,63$ & $10.569,69$ & $18.147,11$ & $0,32 \%$ \\
\hline Trinidad y Tobago & $7.895,71$ & $12.175,83$ & $21.892,77$ & $0,38 \%$ \\
\hline El Salvador & $11.329,56$ & $17.772,28$ & $23.160,37$ & $0,41 \%$ \\
\hline $\begin{array}{l}\text { Bolivia } \\
\text { (Estado Plurinacional de) }\end{array}$ & $9.312,48$ & $13.481,21$ & $24.462,10$ & $0,43 \%$ \\
\hline Paraguay & $11.377,68$ & $14.289,66$ & $24.624,07$ & $0,43 \%$ \\
\hline Panamá & $9.743,19$ & $15.964,80$ & $40.476,20$ & $0,71 \%$ \\
\hline Costa Rica & $14.283,19$ & $23.709,08$ & $42.715,54$ & $0,75 \%$ \\
\hline Uruguay & $21.388,31$ & $28.800,46$ & $47.613,83$ & $0,83 \%$ \\
\hline Guatemala & $19.885,63$ & $29.765,08$ & $47.927,02$ & $0,84 \%$ \\
\hline El Caribe & $34.383,53$ & $43.824,09$ & $62.634,92$ & $1,10 \%$ \\
\hline República Dominicana & $18.497,97$ & $33.337,47$ & $63.688,87$ & $1,11 \%$ \\
\hline Cuba & $44.721,37$ & $38.730,97$ & $70.907,33$ & $1,24 \%$ \\
\hline Ecuador & $38.020,87$ & $46.459,37$ & $85.749,95$ & $1,50 \%$ \\
\hline
\end{tabular}




\begin{tabular}{|l|c|c|c|c|}
\hline \multicolumn{1}{|c|}{ País } & 1990 & 2000 & 2014 & $\begin{array}{c}\text { Porcentaje } \\
\text { sobre PIB total } \\
\text { LAC 2014 }\end{array}$ \\
\hline Perú & $57.864,94$ & $85.464,65$ & $179.635,29$ & $3,14 \%$ \\
\hline Centroamérica (CA4) & $43.603,13$ & $64.719,95$ & $99.917,22$ & $1,75 \%$ \\
\hline Centroamérica (CA6) & $67.629,51$ & $104.393,83$ & $183.108,95$ & $3,20 \%$ \\
\hline Región SICA & $86.657,07$ & $138.680,72$ & $248.352,61$ & $4,34 \%$ \\
\hline $\begin{array}{l}\text { Venezuela (República Boli- } \\
\text { variana de) }\end{array}$ & $143.202,51$ & $176.098,58$ & $256.524,80$ & $4,49 \%$ \\
\hline Chile & $80.233,62$ & $149.161,24$ & $257.861,02$ & $4,51 \%$ \\
\hline Colombia & $147.218,49$ & $192.491,19$ & $349.221,30$ & $6,11 \%$ \\
\hline Argentina & $213.025,90$ & $318.748,06$ & $524.874,89$ & $9,18 \%$ \\
\hline México & $617.851,61$ & $869.293,06$ & $1.175 .563,75$ & $20,56 \%$ \\
\hline Brasil & $1.194 .118,15$ & $1.544 .005,97$ & $2.403 .977,46$ & $42,04 \%$ \\
\hline América Latina & $2.671 .106,92$ & $3.621 .396,82$ & $5.655 .618,05$ & $98,90 \%$ \\
\hline América Latina y el Caribe & $2.705 .490,46$ & $3.665 .220,91$ & $5.718 .252,98$ & $100,00 \%$ \\
\hline
\end{tabular}

Fuente: CEPALSTAT - http://estadisticas.cepal.org/cepalstat/WEB_CEPALSTAT/Portada.asp

La región centroamericana y sus países amigos, junto a varios organismos internacionales, parecen conscientes de este cambio de época y de la necesidad de revisar el modelo actual de desarrollo. Es más fácil detectarlo en el ámbito regional que en el nacional. La naturaleza del pensamiento económico dominante de estos años ha centrado el debate en aspectos macroeconómicos e instrumentales, en la estabilidad y en la apertura como marco para el desarrollo y dejó en segundo plano algunos ámbitos de intervención sectorial de carácter estratégico como el de la agricultura. El sector privado enfoca sus esfuerzos en algunas áreas donde encuentra incentivos a corto plazo (energías renovables) como ha ocurrido en otras épocas (sector financiero, hoteles, construcción y distribución comercial). Aunque no ha sido suficientemente analizado, el modelo económico de estos años no habría cumplido tampoco las expectativas sobre la inversión doméstica porque los sectores donde ésta se concentró han sido adquiridos por la inversión extranjera y no parecen haber generado inversiones derivadas ni un mejor posicionamiento de Centroamérica en las cadenas globales de valor.

Analizando los programas de gobierno de los últimos años en Centroaméri$\mathrm{ca}$, y en ese marco presuntamente propicio para la propuesta neoliberal, se han desarrollado estrategias públicas de desarrollo que han tenido un carácter más bien parcial y limitado, acompañados de inversiones en infraestructuras y de los programas de transferencias condicionadas y en medio de crecientes debates en 
torno a una reforma fiscal que permita aumentar la presión fiscal y dotar de medios al gobierno sin generar efectos negativos en el crecimiento.

Como pasó tras las décadas de implementación de las propuestas estructuralistas, las carencias de la propuesta neoliberal aparecen ahora con mayor intensidad y opacan los efectos positivos de los años previos. CEPAL (2012:250) ha resumido muy bien esta evolución reciente en su documento Centroamérica y República Dominicana: crecimiento, ciclos y transformación económica, 1990-2011, lo que le ha llevado a plantear como resumen del debate la sugerente idea de "crecer para igualar, igualar para crecer":

En los capítulos anteriores se ha puesto de manifiesto que los países de Centroamérica y República Dominicana han tenido avances económicos en los últimos 21 años, materializados fundamentalmente en una reconocida estabilidad macroeconómica tradicional, reflejada en la reducción de los niveles de inflación, abatimiento del déficit fiscal y un moderado crecimiento económico. No obstante estos logros, se advirtió que la subregión enfrenta retos fundamentales. Persiste una polarización económica que ha dificultado el cierre de brechas en términos del PIB per cápita y el rezago de la productividad laboral, el logro de mayores tasas de crecimiento de la actividad productiva y la generación de empleos de calidad. Asimismo, la disminución significativa de la desigualdad y de la pobreza son tareas pendientes, cuyo cumplimiento exige la sociedad. Es urgente que los beneficios del crecimiento se reflejen en mejoras sustanciales del bienestar de la población, en especial en los deciles de ingresos más bajos.

Elemento central de esta problemática es que la subregión muestra, en general, un cociente de inversión muy bajo, una incompleta transformación de la estructura productiva, pues muchos de sus sectores y ramas de actividad se caracterizan por baja productividad y escasa innovación, todo lo cual se traduce en una fuerte restricción externa al crecimiento económico de largo plazo.

\section{CONCLUSIÓN: LA RENOVACIÓN DE LOS EJES DEL DESARROLLO EN CENTROAMÉRICA}

Asistimos entonces a la necesidad de renovar Esquipulas como símbolo del modelo o estrategia de desarrollo. Tras varias décadas de democracia y paz y tras la aplicación de la práctica totalidad de los procesos e instrumentos de desarrollo propiciados por Esquipulas (pacificación, reactivación del proceso de integración, firma del DR-CAFTA y del Acuerdo de Asociación con la Unión Europea, la generalización de la cooperación al desarrollo y de otros mecanismos de finan- 


\section{Pedro Caldentey del Pozo}

ciación externa), la región ha mejorado su situación en términos generales pero sigue sin resolver los problemas estructurales que frenan su desarrollo. No consigue reducir significativamente la inequidad, no gana autonomía económica y se enfrenta a nuevos dramas con la violencia ligada al narcotráfico y las organizaciones criminales.

El propio ex Presidente Vinicio Cerezo de Guatemala, protagonista principal de los acuerdos, más incluso que los ex-presidentes Arias y Ortega, insiste con frecuencia desde su Fundación Esquipulas para la integración Centroamericana, en la necesidad de redefinir Esquipulas, de buscar una nueva etapa en el proceso. En su formulación, todavía imprecisa pero simbólica y políticamente importante, la Fundación plantea un Esquipulas de la integración, basado en políticas sectoriales y temáticas y recuperando las grandes inversiones en infraestructuras como motor de empleo y desarrollo.

Cabe entonces preguntarse cuáles deben ser los elementos del nuevo discurso o la nueva propuesta de desarrollo para la región. En este marco de transición, cualquier reflexión y propuesta debe partir de las siguientes interrogantes:

1. ¿Cuáles han sido los determinantes del modelo de desarrollo de Centroamérica en las últimas décadas: los obstáculos, las políticas, los avances?

2. ¿Cómo debe proyectarse el nuevo debate sobre la gobernabilidad en Centroamérica?: ¿qué deben ofrecer los gobiernos de la región a su ciudadanía tras 25 años de democracia?

3. ¿Cómo defender los intereses de una región pequeña en un mundo con una gobernanza confusa? ¿cómo puede Centroamérica hacer oír su voz en el escenario global?

4. ¿Cuál es el papel de la integración como instrumento de desarrollo para Centroamérica?

El entorno está condicionado por las demandas del cambio de época y ciclo económico, por la eficacia de la propuesta de desarrollo que ofreció Esquipulas y por los desafíos no resueltos por los países centroamericanos. Está también condicionado por la crisis del escenario multilateral y por las dudas sobre los efectos netos de la globalización y animado por la reaparición de iniciativas interregionales que resaltan la relevancia del regionalismo como marco de desarrollo y que recuperan los discursos sobre la integración como un second best.

Ante todo ello, este trabajo presenta como conclusión la necesidad de que la renovación de los acuerdos centroamericanos y de las nuevas estrategias de desarrollo se defina en torno a estos criterios:

1. Es necesaria la reformulación de los retos de la región situando como objetivo principal el déficit del periodo anterior: la promoción de un desarrollo 
basado en la articulación de la promoción del crecimiento económico con las políticas orientadas a combatir la exclusión y centradas en los intereses generales de los países.

2. Las nuevas propuestas deben responder y tener impacto directo o indirecto en torno a asuntos tan determinantes como la promoción de la democracia y la protección de los derechos de los ciudadanos; la consolidación de la capacidad del Estado para ofrecer los servicios que se definan necesarios; la prevención del cambio climático y los efectos de los desastres naturales; la respuesta a la violencia estructural; y la transformación de la estructura productiva y de la competitividad internacional de los países centroamericanos.

3. Centroamérica debe definir sus estrategias de desarrollo a partir de un ineludible enfoque regional, que ya ha sido un elemento central en las décadas previas y que lo será en las próximas; que supera los límites de la integración y del actual SICA por lo que necesita de la cooperación entre gobiernos e instituciones publica y entre los actores privados de la región; y que debe resolver los problema de eficacia y eficiencia de etapas anteriores.

4. Los países centroamericanos debe definir con precisión el alcance de los instrumentos regionales de desarrollo. En general, el desarrollo de la acción conjunta regional exige acuerdos precisos y sostenidos sobre sus alcances y sobre los recursos que los países miembros aportarán a sus iniciativas.

5. En particular, y aprovechando el final de los períodos transitorios de desgravación de los acuerdos comerciales de la región con países terceros, los gobiernos centroamericanos deben superar el escenario de la negociación comercial descoordinada. Deben definir los alcances y límites de su intención de ejecutar una política de negociación comercial conjunta que ofrezca a su sector empresarial un panorama claro de las oportunidades comerciales con terceros países y que permita explorar eficientemente las posibilidades del mercado interno regional.

En otros trabajos (Caldentey 2014) hemos planteado los retos particulares del SICA. La integración regional es un ámbito relevante para casi todos ellos aunque siempre como un ámbito complementario al de las políticas nacionales de desarrollo. No obstante, la región debe aprovechar el marco de la integración centroamericana como legado de los Acuerdos de Esquipulas para definir consensos regionales que fortalezcan las oportunidades de los países centroamericanos en esta nueva etapa.

\section{BIBLIOGRAFÍA}

ALONSO, J. A. (2013), Cooperación con países de renta media. Un enfoque basado en incentivos, ed. SGCID (Ministerio de Asuntos Exteriores y de Cooperación de España), Madrid. 
BANCO MUNDIAL (2011), Crimen y violencia en Centroamérica. Un desafío para el desarrollo, edita Banco Mundial, Washington.

BÁRCENA, A. y PRADO, A. (editores) (2015), Neoestructuralismo y corrientes heterodoxas en América latina y el Caribe a inicios del siglo XXI, edita CEPAL-IDRC, Santiago de Chile.

BRICEÑO RUIZ, J.; RIVAROLA PUNTIGLIANO, A. y CASAS GRAGEA, A. (editores) (2012), Integración latinoamericana y caribeña. Política y economía, Fondo de Cultura Económica, Madrid.

BULL, Benedicte (2014), "Towards a Polítical Economy of Weak Institutions and Strong Elites in Central America". European Review of Latin American Studies, nº7, October, pp. 117-128.

CALDENTEY, P. (2000), El desarrollo económico de Centroamérica en el marco de la integración regional, Banco Centroamericano de Integración Económica (BCIE), Honduras.

CALDENTEY, P. (2012), "La Integración Regional, ámbito emergente de políticas de desarrollo en Centroamérica”, Revista española de Desarrollo y Cooperación, 30, pp. 85-103.

CALDENTEY, P. (2013), "La integración regional, marco de la cooperación horizontal en América Latina”, pp. 189-204. En Salvador Arriola, Rafael Garranzo y Laura Ruiz Jiménez (coordinadores), La renovación de la cooperación iberoamericana. Transformaciones para una agenda post 2015, editan SEGIB y AECID.

CALDENTEY, P. (2014), Los desafíos de la Integración Centroamericana. Serie estudios y perspectiva 156, CEPAL, México.

CALDENTEY, P., ROMERO, J. J. (2010) (editores), EL SICA y la UE. La integración regional en una perspectiva comparada. Fundación ETEA para el Desarrollo y la Cooperación. Colección de estudios centroamericanos $\mathrm{N}^{\circ} 1$.

CASAS A. y CALDENTEY P. (2015), "The Crisis of the European Integration Model, and its Implications for Latin American Integration", p. 112-125. In Roy, J. (editor) (2015), A New Atlantic Community: The European Union, the US and Latin America, edited by Miami-Florida European Union Center/Jean Monnet Chair, Miami (USA).

CEPAL (2014), Balance Preliminar de las Economías de América Latina y el Caribe 2014, ed. CEPAL, Santiago de Chile.

CEPAL (2013), Estudio económico para América Latina y el Caribe. Tres décadas de crecimiento desigual e inestable, CEPAL, División de desarrollo económico, Santiago de Chile.

CEPAL (2012), Centroamérica y República Dominicana: crecimiento, ciclos y transformación económica, 1990-2011, CEPAL, México.

CLOSE, D., MARTÍ i PUIG, S. y MCCONNELL S. A. (2011), The Sandinistas and Nicaragua Since 1979, Boulder, Lynne Rienner. 
CORDERO, M. (2014), El comercio de bienes y servicios en Centroamérica, 2014, ed. CEPAL, México.

EVENETT, S. and VINES, D. (2012), "Crisis-era protectionism and the multilateral governance of trade: an assessment", Oxford Review of Economic Policy, vol 28, No. 2, Summer 2012, pp. 195-210.

FIORENTINO, R. V. (2011), "The never-ending story of regional trade agreements", pp. 3-30. In JOVANOVIC, M. Editor (2011). International Handbook on the Economics of Integration, vol I, General Issues and Regional Groups, Edward Elgar Publishing. UK.

INSTITUTO CENTROAMERICANO DE ESTUDIOS FISCALES (2015). Perfiles macrofiscales de Centroamérica, n5, año 2, ed. ICEFI, Guatemala.

INSTITUTO CENTROAMERICANO DE ESTUDIOS FISCALES (2012), La política fiscal de Centroamérica en tiempos de crisis, ed. ICEFI, Guatemala.

LE GOOF, M. y Jan SIINGH, R. (2013), Does trade reduce poverty? A view from Africa. Policy Research Working Paper 6327. The World Bank. Africa Region. Poverty Reduction and Economic Management.

LIPSEY R. G. y SMITH, M. G. (2011), "Multilateral versus regional trading arrangements: substitutes or complements?", pp. 90-120. In JOVANOVIC, M. Editor (2011), International Handbook on the Economics of Integration, vol. I. General Issues and Regional Groups, Edward Elgar Publishing, UK.

LÓPEZ, H. y SHANKAR, R. (2011), Getting the Most Out of Free Trade Agreements in Central America, ed. Banco Mundial.

MONTOBBIO, Manuel (2012), Esquipulas II + 25: Centroamérica en perspectiva. Notes internacionals CIDOB, Barcelona.

PÉREZ CALDENTEY, E. (2015), "Una coyuntura propicia para reflexionar sobre los espacios para el debate y el diálogo entre el (neo) estructuralismo y las corrientes heterodoxas", pp. 35-83, en BÁRCENA, A. y PRADO, A., editores (2015), Neoestructuralismo y corrientes heterodoxas en América latina y el Caribe a inicios del siglo XXI, edita CEPAL-IDRC. Santiago de Chile.

PROGRAMA ESTADO DE LA NACIÓN (2014), Estadísticas de Centroamérica 2014, edita Programa Estado de la Nación, San José.

PROGRAMA ESTADO DE LA NACIÓN-REGIÓN (2011),"Estado de la región en desarrollo humano sostenible 2011. Un informe desde Centroamérica y para Centroamérica", Programa Estado de la Nación, San José de Costa Rica.

RODRIK, D. (2011). La paradoja de la globalización, Antoni Bosch Editores, Barcelona.

ROJAS ARAVENA, F. (2012b) (Editor), América Latina y el Caribe: Relaciones Internacionales en el siglo XXI. Diplomacia de Cumbres y espacios de concertación regional y global. Teseo, Buenos Aires. ROJAS ARAVENA, 


\section{Pedro Caldentey del Pozo}

F. (2012c) (Editor), América Latina y el Caribe: Vínculos globales en un contexto multilateral complejo, editorial Teseo-Secretaría General de FLACSO, Buenos Aires.

ROJAS, F, y CALDENTEY, P. (2013), "Central American's relation with Latin America”, pp. 322-335. En SANCHEZ-ANCOCHEA, D. Y MARTÍ, S. Handbook of Central Americana Governance, Routledge. UK.

SANAHUJA, J. A. (2012), "La crisis europea y América Latina y el Caribe: mutaciones y reequilibrios en las relaciones birregionales", pp 105-151, en: Rojas Aravena, F. (Editor), América Latina y el Caribe: Relaciones Internacionales en el siglo XXI. Diplomacia de Cumbres y espacios de concertación regional y global, Teseo-FLACSO, Buenos Aires.

SANAHUJA, J. A. (2012b), "Regionalismo postliberal y multilateralismo en Sudamérica: el caso de UNASUR", pp. 19-72. En SERBIN, A.; MARTÍNEZ, L.; y RAMANZINI, H. (coordinadores) (2012), El regionalismo postliberal en América Latina y el Caribe: nuevos actores, nuevos temas, nuevo desafíos, CRIES, Buenos Aires.

SANCHEZ-ANCOCHEA, D. y MARTÍ, S. (2014), "Central America's triple transition and the persistent power of the elite", pp. 4-22, en SANCHEZ-ANCOCHEA, D. Y MARTÍ, S. (2014), Handbook of Central Americana Governance, Routledge, UK.

SANTOS, F. (2013), "Cambios en el escenario del regionalismo latinoamericano. Del regionalismo abierto al regionalismo postliberal". En SANTOS Y POZO, O. (2013), El SICA: diálogos sobre una integración dinámica y singular en América Latina. Fundación ETEA para el Desarrollo y la Cooperación. Colección de estudios centroamericanos $\mathrm{N}^{\circ} 4$.

SCHWARTZ, J. (2012), Logistics in Central America: The Path to Competitiveness - Summary Document, The World Bank.

SECRETARIA DE LA INTEGRACIÓN ECONÓMICA CENTROAMERICANA (2014), Estado de situación de la integración económica centroamericana, ed. SIECA, Guatemala.

SEGOVIA, A. (2005), Integración real y grupos de poder en América Central: implicaciones para el desarrollo y la democracia de la región, ed. Frederich Ebert Stiftung, Costa Rica.

TORRES-RIVAS, E. (2011), Revoluciones sin cambios revolucionarios, F\&G editores, Guatemala.

UNDP (2014), Human Development Report 2014, ed. UNDP, New York.

UNITED NATIONS (2013), A new global partnership: Erradicate poverty and transform economies through sustainable development. The Report of the HighLevel Panel of Eminent Persons on the Post-2015 Development Agenda, United Nations Publications, New York. 
WATKINS, K. (2013), Leaving no one behind: an equity agenda for the post 2015 goals, Oververseas Development Institute, UK.

WONNACOTT, P. y WONNACOTT, R. J. (2011), "The economic case for reciprocal trade negotiations: gains from both imports and exports", pp.167-186. In JOVANOVIC, M. Editor (2011). International Handbook on the Economics of Integration, vol. I, Edward Elgar Publishing, UK. 